Down Syndrome Research and Practice Vol 5, No.2, pp 88 - 92.

(C) The Down Syndrome Educational Trust

Printed in Great Britain. All rights reserved.

ISSN: 0968-7912 (1998) 5:2

\title{
THE GROUP: AN INSTRUMENT OF INTERVENTION FOR THE GLOBAL DEVELOPMENT OF THE CHILD WITH DOWN SYNDROME IN THE PROCESS OF SOCIAL INCLUSION.
}

\author{
Rosa Borbones Lloveras \\ Fundacio Catalana Sindrome de Down, Barcelona, Spain \\ Marta Golano Fornells \\ Fundacio Catalana Sindrome de Down, Barcelona, Spain
}

\begin{abstract}
We present our experience with groups using symbolic games for children with Down syndrome between 7 and 10 years old. In the results, we have observed a clear evolution in the game levels and the interaction strategies. We have witnessed how the child is capable of organising progressively his or her own activity in an autonomous manner, how he/she becomes interested in the others in the group and the difficulties arising in the process. The child appears in front of the rest with his/her own peculiarities. From his/her own process of becoming aware, there appear a number of important elements in the process of construction of his/her own personal identity.
\end{abstract}

Keywords: Down syndrome, child, play, social skills, peers, identity

\section{Introduction}

The Fundació Catalana Síndrome de Down was founded in 1984. It has been offering different services such as: Early intervention, Resource Center Follow-up Program during schooling, Leisure Time, Document Center, Down Syndrome Medical Center, Work Integration, Training, Teaching and Research, and Publications with the objective of improving the standard of living in people with Down syndrome. Since its creation, the Fundacio Catalana Sindrome de Down has worked with the objective of achieving a better quality of life for people with the Down syndrome.

With this objective, we have put in practice a number of projects based on group work as an intervention instrument in the integration process. The group offers a relational context within which relationships between members of a similar socio-personal status can take place.
These relationships have a fundamental function in the socio-cognitive development, since they allow the construction of the relational competencies necessary for a satisfactory social integration and personal development. Besides, the group includes the fundamental elements for the exploration of their own identity; recognising the disability and establishing the various differences existing within the Down syndrome community.

\section{The educational integration}

The process of school integration has no meaning if not understood from a global perspective. From this point of view, such integration:

- involves more than learning experiences including those aspects of the curricula referred to as interpersonal relationships as well as levels of social and intellectual autonomy. 
- at the same time, the process of educational integration is part of a broader social integrational process in which the child with intellectual disabilities participates in activities such as leisure time or in activities where the time is not structured by the adult.

Such a broader consideration of the process referring to educational integration, emerges from observing the difficulties and needs which are manifested in the social context on a daily basis. In the regular educational context, the child with Down syndrome is involved in situations in which his/her disabilities become obvious. This happens not only in learning experiences, but also in non-structured situations in which children with Down syndrome relate to other children with no disabilities. In these social contexts, it becomes evident that such relationships do not function as typical "peer relationships".

According to Willard Hartup (1983), the term "peer relationships", refers exclusively to those social relationships in which the participants are on similar developmental and socio-personal levels. In most occasions the interaction between the child with Down syndrome and children with no disabilities does not meet such conditions.

We refer for example, to behaviours of rejection or overprotection that are observed in the relationship. Who has not seen the teacher avoiding arguing with the child with Down syndrome because such behaviour is not tolerable by the rest of the class? Who has not heard of the untouchable child?

We are not trying to say that in the regular school the child with Down syndrome cannot have relationships with peers with the same socio-personal level, but we believe that it is more difficult. In the regular school, aside from those mentioned above, other types of heterogeneous relationships may occur, referring to age and socio-personal status (in which there are support strategies, adjustments to the level of the other's ability, reciprocal imitation, etc) which are as important for the socio-cognitive development as those already discussed.

Consequently, we understand that it is essential to offer children with intellectual disabilities who attend regular schools, relational contexts in which they can have the opportunity to have those personal experiences that only appear in a relationship between peers with the same sociopersonal status such as complicity, confrontation, reciprocity..., and as a last resort friendship.
Relationships that serve a specific function in the social development, facilitating the construction of relational competencies which are needed for the social integration and the global satisfactory development of the person.

\section{The group: A model of intervention for integration}

For five years, since the creation of the Follow-up Program during Schooling, the type of treatment has been redefined, shifting from a personalised to a group mode of intervention, not discounting totally the first approach mentioned. Such approach through group intervention has meaning, only if considered from the perspective of diverse environments, starting from educational integration. We believe that participation in different type of groups may offer each person with the answer to his/her varied needs. Why do we think group intervention is so important?

People with Down syndrome integrated in regular schools are the only representative of the disability in the vast majority of the schools they attend. In other occasions, there are 2, 3 or 4 children with Down syndrome or with some kind of disability. Such a fact, shows the loneliness of the person with Down syndrome in relation to his own difference.

In the regular school, the person with disability runs the risk of identifying himself/herself with his/her own disability, given the fact that he/she feels differently from the others and has little in common with them.

In order for this not to happen, we believe that the study of similarities and differences in the diverse collective - through which each person's life goes by - is an essential element for the construction of self-identity: a fundamental piece of work in both groups.

By reflecting on those characteristics that make one's self similar or different from the others, it will be possible to discover one's own singularity.

The importance of the "peer group with the same socio-personal status" - understood as a group of people who share the same disability and chronological age - lies in various aspects.

The groups that we offer allow children with Down syndrome to come together in such a peer group.

Firstly, the group facilitates an essential element for the conquest of self-identity: the 
acknowledgement of their own disability. Pretending that the disability does not exist, creates a false and distorted sense of reality. Such acknowledgement asks for words, gestures and attitudes, an insight of what reality really is.

Secondly, the group confirms also the many existing differences. The members analyse, observe and reflect on what they may do, how they are, what they like to do to confirm that differences exist, as in any other collective. There are also many differences among people with Down syndrome.

\section{Symbolic play group}

The following experience has been carried out with children aged 7 to 10 , integrated in regular schools, who attend symbolic play sessions in the Down Syndrome Centre once a week during 2 years approximately.

This space of psychopedagogical intervention was created with the double aim of play and interaction. We start from symbolic play behaviours since spontaneous activity is the one practised by children at this age. Behaviours where they create, re-structure or re-invent real life situations through the fictional dimension. Play is, at the same time, an activity that children do spontaneously with others, and where their own interests come up.

\section{Organization and development of the play space}

For the group materials related to symbolic play have been presented in the play space, representing different moments of daily, domestic and social life. The same material has been used during four consecutive sessions. During the first two, the group paired up and in the last two the group stayed as a whole.

\section{Intervention}

Two female adults have been present in the sessions. Firstly, they had the intention of establishing a framework and setting limits, and secondly, they intervened directly on the behaviour of each group member.

The intervention pointed at the development of the way of the play, and the relation to more developed levels, that may allow children a greater structuring of the physical and social environment.

According to this, the adult has taken part in:

1. the play

2. the interactions

3. the insight of the play and the interactions.
1. Has taken part in the play:

1.1 facilitating the attribution of symbolic meaning to the activity.

1.2 facilitating verbal expression of the meaning of the play and the use of words as an enriching element.

1.3 framing the play in larger symbolic contexts helping in the sequencing.

For example: in the case of a child who gives an injection to his/her friend.

The intervention will try to:

- make explicit the action of 'giving an injection'.

- show the role of each one of the members; the doctor and the patient.

- and the activity that they carry out; that of 'the doctor who cures and that of the patientkid who is ill'.

- the different ways of becoming ill; 'what's wrong with the kid? Headache, sore throat...

\section{Has taken part in the interactions:}

2.1 encouraging the interest towards the other's play.

2.2 facilitating the relationship between the members through the meeting of individual or parallel play.

2.3 acting as a mediator in conflict situations to state the social conflict as well as reflecting on the different conflicting perspectives and the choices for answers.

\section{Has taken part in the insight of the play and the interactions:}

3.1 promoting verbal expression of the play: actions, roles, sequences...

3.2 promoting verbal expression of the interactions: who played with whom, if they had a good time, which attitudes came up, which conflicts, etc.

\section{Conclusions}

The experience will be presented concisely taking into consideration two main aspects of such experience:

- the interaction among members

- the play activity

The relational dimension appeared as an organiser of the experience. That is the reason for the results to be presented as part of this essential topic, differentiating 3 stages, determined by the group organisation observed. (Such stages have been interpreted qualitatively starting from our observations with some members and a very concrete situation, therefore, we do not intend to make any sort of generalisations). 
We could start by mentioning each one of the groups as a collection of individuals, who would introduce themselves to the rest in a very defined way, keeping to a minimum the number of interactions. These interactions characterised by their rigidity; rigidity concerning the members of the relationship, and the roles played by them. They were interactions in which there was not an exchange of perspectives, but a level of unilateral relationship (Selman, 1985). The play activity was limited to the conventional use of the objects with a sequence in the case of older girls, and an absence of this in younger boys. The limited verbalisations that accompanied the individual or parallel play made impossible any kind of interaction.

The second stage observed was characterised by the gradual flexibility, compared to the rigid interactions mentioned before. Flexibility concerning the participants with whom they interacted, and the roles played by them. The intervention in pairs had a decisive impact in this aspect. As a result, there was a preference to relate to one person more than to others. In this second phase, the game was more elaborate since the couple situation has allowed the opportunity of enriching it, and due to the intervention in this sense.

After some time in this second phase, there appeared a spontaneous activity which left out the proposed play materials; the clapping game, a game which is done clapping hands while singing a song. In this activity, they were able to enjoy their relational preferences.

In this second stage and as a derivation of the conflicts arisen because of the material, the game that we will call the 'stealing materials' game, took place. It arose as a strategy to resolve conflicts and turned into an activity in itself that they all enjoyed. Paradoxically, this activity generated a group relationship. This happened because all the members of the group shared an implicit agreement on the activity that they would carry out and the roles that they would perform: in other words, those who steal and those from whom they steal; roles that alternated.

Progressively, the stealing activity was disappearing, resulting in a dynamic of group relationships without losing the pair ones. In other words, both ways of relationship occurred simultaneously. During this moment, each one of the members showed interest openly for the rest of his/her peers. But comparably to this qualitative change, the problem resided in the absence and difficulties regarding the relational strategies with which to carry out greater interest in the relationship.

Finally, in the process of becoming aware of the game and the interactions that had taken place, it was observed how boys and girls without the material were able to progressively represent mentally those situations they experienced. They were able to share what kind of game they played, what they did and with whom, if there were any fights, how they happened, why...

The fact that they were able to look at themselves and to reflect on the activity and the interactions, has shown the diverse personalities and functioning of each of the members of the group. Each of them presented him/herself with his/her own singularities. On the one hand, through their characteristic features of each of them in relation to the others and the group (the range of difference varied from wearing glasses or not, being more active, or more talkative, having less problems expressing him/herself, preferences to play, etc), and on the other, through similarities among the members of the group.

A critical element for the development of selfidentity has been shown throughout the sessions: Boys and girls outlined to the therapists issues related to being a child with Down syndrome in many different ways. M., an 8 year old girl said: "the children of the group are my siblings", J. a 7 year old said: "the children of the group are dumb", "I don $t$ like them". These and other affirmations that appeared led to put into words the meaning of being a child with Down syndrome. To be able to talk about the children with Down syndrome as dumb or as those who behave in a silly way, or to think of what makes them siblings, or what they have in common or what makes them different from each other, or to be able to express their anger with themselves and the others, understanding the difficulty in growing up but helping them discover and value their own potential. All of this brings a new dimension to the person with Down syndrome: the access to self-knowledge and to its acceptance.

It is considered -after what was discussed- that the peer group with the same socio-personal status, appears as a valid tool to participate and promote the total development of the person with Down syndrome. Totality that includes the symbolic, intellectual, relational, social and also the affective development and personality. Such a modality of intervention is considered as being a necessary part in the process of socioeducational integration; understanding this from a broader point of view than has been presented 
previously. Here, we have only discussed the process of social integration from the point of view of the child with Down syndrome. It would be for future considerations to discuss the interventions and modifications to carry out in the school and ultimately in the society.

\section{Correspondence:}

Rosa Borbonès. Fundació Catalana Síndrome de Down, València 229, pral. 08007 Barcelona SPAIN. Tel. 34-3-215.74.23. Fax: 34-3-

215.76.99.E-mail: fcsd@nexus.es.

Note: From a paper presented in October 1997, at The 6th World Congress on Down Syndrome, Madrid, Spain.

\section{References}

Cicchetti, D. \& Beeghly, M. (1990). Children with Down syndrome: A developmental perspective. Cambridge University Press, Cambridge.

Grinberg, L. (1973). Adolescencia, identidad e ideología. En Psicopatología y Psiquiatría del adolescente. Editorial Paidós.

Hartup, W. (1983). Peer relations. In: Mussen, P.H. (Ed.). Handbook of child psychology (Vol. 4): Socialization, personality and social development (4th Ed.).

Piaget, J. (1984). La formación del símbolo en el niño. México: Fondo de Cultura Económica. (1st Ed., 1959 ).

Sastre, G. Y \& Moreno, M. (1980). Descubrimiento y construcción de conocimientos. Barcelona: Gedisa.

Selman, R.L. (1985). The use of interpersonal negotiation strategies and communicative competencies: a clinical-developmental exploration in a pair of troubled early adolescents. In Hinde, R.A., Perret-Clermont, A.N. \& Stevendon-Hinde, J. (Eds.). Social relationships and cognitive development. Oxford: Clarendon Press.

Serafica, F. (1990). Peer relations of children with Down Syndrome. In Cicchetti, D \& Beeghly, M. (Edit.) Children with Down syndrome. A developmental perspective. Cambridge University Press, Cambridge.

Shure, M.B., Spivack, G. \& Platt, J.J. (1976). The problem solving approach to adjustment: A guide to research and intervention. San Francisco, California: Jossey-Bass. 